\title{
Clinical Profile and Management Techniques of Surgical Obstructive Jaundice Cases in a Tertiary Center at Bareilly
}

\author{
Shailendra Kumar Singh ${ }^{1}$ Porus Choudhary ${ }^{2}$ Ruby Yadav ${ }^{3}$ \\ ${ }^{1}$ Department of General Surgery, Dr. Ram Manohar Lohia Hospital \& \\ PGIMER, New Delhi, India \\ ${ }^{2}$ Department of General Surgery, Lady Hardinge Medical College, \\ New Delhi, India \\ ${ }^{3}$ Department of Obstetrics and Gynaecology, Lady Hardinge \\ Medical College, New Delhi, India \\ Int J Recent Surg Med Sci 2019;5:26-30
}

\begin{abstract}
Address for correspondence Shailendra Kumar Singh, MBBS, MDS, Department of General Surgery, Dr. Ram Manohar Lohia Hospital \& PGIMER, Gole Market, New Delhi 110001, India (e-mail: drshailendra.kumar7@gmail.com).
\end{abstract}

\begin{abstract}
Introduction Obstructive jaundice is associated with high morbidity and mortality. Obstructive jaundice is not a definitive diagnosis. Detailed evaluation to establish the etiology of the cholestasis and cause of obstruction is crucial to avoid secondary pathologic changes and to plan different surgical techniques to intervene at an early stage.

Materials and Methods A cross-sectional study was conducted among 50 cases of surgical obstructive jaundice at Shri Ram Murti Smarak Institute of Medical Sciences (SRMSIMS), Bareilly.

Results The mean age of this study population was $48.44 \pm 8.2$ years, and $48 \%$ (24) patients had obstructive jaundice of benign etiology, whereas $52 \%$ (26) had malignant etiology. Among males, the common presentation was choledocholithiasis in benign disease and carcinoma of the gallbladder among malignancy. In females also, disease presentation was similar to that of males. Percutaneous transhepatic biliary drainage (PTBD) was the most common method of biliary decompression in malignant

Keywords

- obstructive jaundice

- clinical profile

- management techniques

- surgical obstructive jaundice

- SRMSIMS group. For biliary decompression in patients of benign etiology, common bile duct (CBD) exploration with T-tube drainage was done in most cases.

Conclusion Obstructive jaundice has different etiologic spectrum in both males and females. Irrespective of etiology, common presentation was pain ( $94 \%$ of the cases). Most patients with malignant etiology presented with palpable lump. PTBD was the most common method of biliary decompression in malignant group. CBD exploration with T-tube drainage has higher values of decrease in serum bilirubin, serum bilirubin (indirect), serum alkaline phosphatase, and albumin.
\end{abstract}

\section{Introduction}

Jaundice (derived from French word "Jaune" for yellow) or icterus (Latin word for "Jaundice") means yellowish staining of the skin, sclera, and mucous membranes due to deposition of bilirubin (a yellow orange bile pigment) in these tissues. ${ }^{1,2}$ Jaundice was once called the morbus regius (the regal disease) in the belief that only the touch of a king could cure it. Jaundice can be classified into pre- or posthepatic. The causes of posthepatic jaundice (obstructive or surgical cholestasis) are more relevant to surgeons. Patients with obstructive jaundice have very high morbidity and mortality; early diagnosis of the cause of obstruction is very important, especially in malignant cases, as resection is only possible at an early stage. Obstructive jaundice is not a definitive diagnosis, and early evaluation to establish the etiology of the cholestasis is crucial to avoid secondary pathologic changes (e.g., secondary biliary cirrhosis) if obstruction is not relieved. ${ }^{3}$ Obstructive jaundice is the most common type with which the surgeon has to deal. It has its origins in the liver and is due to gradual or sudden, partial or complete, temporary or permanent obstruction, either received

March 10, 2019

accepted

April 16, 2019
DOI https://doi.org/

$10.1055 / \mathrm{s}-0039-1692381$

ISSN 2455-7420.
C2019 Medical and Surgical Update Society
License terms

$($ () (1) $\Theta \circledast$ 
within or without the ducts to the flow of bile. Complete or partial obstruction may result from tumor formation at the papilla of Vater, in the common bile duct (CBD), in the head of pancreas, or it may be due to stone formation and stricture of papilla of Vater, stricture of CBD, or hepatic duct. ${ }^{4,5}$ While it is possible for small stones to pass through the papilla of Vater, larger ones will lodge at this point, with increased obstruction as the result of inflammation caused by their presence. Biliary obstruction results in hepatocyte disfunction and release of enzymes into circulation such as transaminases, alkaline phosphatase (ALP), bilirubin, etc. ${ }^{6,7}$ Estimation of serum albumin in obstructive jaundice indicates the synthetic function of the liver. Increased nitric oxide production in hepatocytes is involved in liver dysfunction following obstructive jaundice. Obstructive jaundice damages critical functions in the liver. However, the mechanisms involved in hepatic dysfunction are obscure. Nitric oxide is implicated in liver injury under various pathologic conditions. Derangement of liver functions in obstructive jaundice has been known to influence surgical outcome. ${ }^{8,9}$ The pattern and time frame of liver function recovery in patients with surgical obstructive jaundice undergoing a bilioenteric anastomosis has not been comprehensively defined in human beings. Liver function tests by themselves do not contribute to etiology or the lesions leading to surgical obstructive jaundice, and other radiologic and endoscopic investigations are necessary before surgical treatment. None of the liver function test enables the surgeon to accurately assess the functional capacity of the liver while investigations recommended should be performed in a standardized manner. Obstructive jaundice poses diagnostic challenge to general surgeon practicing in resource-limited countries. This study is conducted to understand the clinical profile and different management techniques of surgical obstructive jaundice cases.

\section{Materials and Methods}

\section{Study Design}

This is a cross-sectional, descriptive study.

\section{Study Setting}

This study was conducted at Shri Ram Murti Smarak Institute of Medical Sciences (SRMSIMS), Bareilly, a tertiary care teaching hospital.

\section{Study Duration}

This study was conducted between January 2012 and August 2013.

\section{Patient Enrollment}

A total of 50 patients with clinical diagnosis of surgical obstructive jaundice attending outpatient department, emergency, and those referred from medicine department were studied consecutively. Patients who were willing to participate in the study and those who had given consent were included.

\section{Data Collection}

Detailed history and clinical examination and investigation were performed using a predesigned questionnaire. Biochemical parameters such as serum bilirubin, serum glutamic oxaloacetic transaminase (SGOT), serum glutamic pyruvic transaminase (SGPT), ALP, prothrombin time (PT), serum protein albumin, and serum amylase were analyzed. All biochemical investigations were done on autoanalyzer machine BS380 MINDRAX; coagulation machine SYSMEX CA-50 and Coulter counter were used for hematology.

\section{Statistical Analysis}

Data were entered in the Microsoft Excel spreadsheet version 2013 and analyzed. Quantitative variables were described in the form of means and standard deviations. Qualitative variables were described in the form of frequency and percentages. Data representation was done in tables as represented below.

\section{Results}

During the study period, a total of 50 patients of obstructive jaundice were enrolled. Out of these, 34 (68\%) patients were females and 16 (32\%) were males. Male-to-female ratio was $8: 17$. There ages ranged from 20 to 79 years, with mean age of $48.44 \pm 8.2$ years. Most of the female patients ${ }^{10}$ were between age group of 40 and 49 years, whereas majority of male patients ${ }^{5}$ were between age group of 60 and 69 years; $48 \%$ (24) patients had obstructive jaundice of benign etiology whereas 52\% (26) had malignant etiology (-Tables 1, 2).

Among males, choledocholithiasis was a common presentation in benign etiology, and carcinoma gallbladder was a common presentation among malignancies. In females also, disease presentation is in similar lines with males, but with respect to malignancies, five cases of cholangiocarcinoma have been observed ( - Table $\mathbf{3}$ ).

Most patients, irrespective of etiology, presented with pain (94\%), followed by pruritus (40\%); $30 \%$ of patients, mostly of malignant etiology, presented with palpable lump, and $54 \%$ of patients with carcinoma of the gallbladder presented with palpable mass, thus supporting Courvoisier's law. Scratch marks were seen in equal percentage of patients among the benign and malignant conditions (-Table 4).

Percutaneous transhepatic biliary drainage (PTBD) was the most common method of biliary decompression in malignant group as most patients came in advanced malignant stage. PTBD was done as palliative procedure in 17 cases. Whipple's operation was done in five cases (carcinoma head of pancreas, periampullary carcinoma, and cases of cholangiocarcinoma). Hepaticojejunostomy and choledochoduodenostomy was done in one case each. For biliary decompression in patients of benign etiology, CBD exploration with T-tube drainage was done in 20 cases. Four patients were referred for endoscopic retrograde cholangiopancreatography (ERCP) or stenting. 
Table 1 Age- and sex-wise distribution of cases

\begin{tabular}{|l|l|l|l|l|l|l|}
\hline Age group $(\mathrm{y})$ & Male & $\%$ & Female & $\%$ & Total & $\%$ \\
\hline$<20$ & 0 & 0 & 0 & 0 & 0 & 0 \\
\hline $20-29$ & 1 & 2 & 4 & 8 & 5 & 10 \\
\hline $30-39$ & 2 & 4 & 4 & 8 & 6 & 12 \\
\hline $40-49$ & 3 & 6 & 14 & 28 & 17 & 32 \\
\hline $50-59$ & 4 & 8 & 4 & 8 & 8 & 16 \\
\hline $60-69$ & 5 & 10 & 4 & 8 & 9 & 18 \\
\hline $70-79$ & 1 & 2 & 4 & 8 & 5 & 10 \\
\hline$>79$ & 0 & 0 & 0 & 0 & 0 & 0 \\
\hline Total & 16 & 32 & 34 & 68 & 50 & 100 \\
\hline
\end{tabular}

Table 2 Etiology-wise distribution of cases

\begin{tabular}{|c|c|c|c|c|c|c|c|}
\hline Type & Etiology & Male & $\%$ & Female & $\%$ & Total & $\%$ \\
\hline \multirow[t]{4}{*}{ Benign } & Choledocholithiasis & 8 & 16 & 11 & 22 & 19 & 38 \\
\hline & CDC & 0 & 0 & 1 & 2 & 1 & 2 \\
\hline & Benign CBD stricture & 0 & 0 & 2 & 4 & 2 & 4 \\
\hline & Mirizzi’s syndrome & 1 & 2 & 1 & 2 & 2 & 4 \\
\hline \multirow[t]{6}{*}{ Malignant } & CA gallbladder & 4 & 8 & 11 & 22 & 15 & 30 \\
\hline & CA pancreas & 0 & 0 & 1 & 2 & 1 & 2 \\
\hline & Periampullary CA & 2 & 4 & 2 & 4 & 4 & 8 \\
\hline & Cholangio CA & 0 & 0 & 5 & 10 & 5 & 10 \\
\hline & Hepatocellular CA & 1 & 2 & 0 & 0 & 1 & 2 \\
\hline & Total & 16 & 32 & 34 & 68 & 50 & 100 \\
\hline
\end{tabular}

Abbreviations: CA, carcinoma; CBD, common bile duct; CDC, choledochal cyst.

Table 3 Clinical features by etiology

\begin{tabular}{|l|l|l|l|l|l|l|l|}
\hline Type & Etiology & $N$ & Pain & Fever & Lump & Pallor & Others $^{\text {a }}$ \\
\hline Benign & Choledocholithiasis & 19 & 18 & 2 & 1 & 6 & 11 \\
\hline \multirow{5}{*}{ Malignant } & CDC & 1 & 1 & 0 & 0 & 0 & 0 \\
\cline { 2 - 8 } & CBD stricture & 2 & 2 & 1 & 0 & 1 & 2 \\
\cline { 2 - 8 } & Mirizzi's syndrome & 2 & 2 & 1 & 0 & 0 & 1 \\
\hline \multirow{5}{*}{} & CA gallbladder & 15 & 14 & 7 & 8 & 7 & 1 \\
\cline { 2 - 8 } & CA pancreas & 1 & 0 & 0 & 0 & 0 & 1 \\
\cline { 2 - 8 } & Periampullary CA & 4 & 4 & 1 & 2 & 2 & 2 \\
\cline { 2 - 8 } & Cholangio CA & 5 & 5 & 4 & 3 & 3 & 2 \\
\cline { 2 - 8 } & Hepatocellular CA & 1 & 1 & 0 & 1 & 1 & 0 \\
\cline { 2 - 7 } & Total & 50 & 47 & 16 & 15 & 20 & 20 \\
\hline
\end{tabular}

Abbreviations: CA, carcinoma; CBD, common bile duct; CDC, choledochal cyst.

apruritus/clay-colored stools/high-colored urine.

Biochemical Findings in Percutaneous Transhepatic Biliary Drainage versus Common Bile Duct Exploration of Management

- Serum bilirubin: There was significant decrease in serum bilirubin (direct) after PTBD. In nearly $88.23 \%$ of patients, the decrease in serum bilirubin was in between 10 and $50 \%$ of the initial preoperative value. In $5.8 \%$ of patients, fall in bilirubin was greater than $50 \%$. In biliary decompression following CBD exploration with T-tube drainage there, $75 \%$ patients had decrease in serum bilirubin between 10 and $50 \%$. In $15 \%$ of patients, the decrease in serum bilirubin was more than $50 \%$.

- Serum bilirubin (indirect): Following biliary decompression after PTBD, the fall in serum bilirubin (indirect) was between 10 and $50 \%$ in $64.7 \%$ of patients. In $35 \%$ of patients, the fall in serum bilirubin indirect was more than 50\%. After CBD exploration with T-tube drainage, the decrease in serum bilirubin indirect was between 10 and $50 \%$ in $25 \%$ of patients. In $55 \%$ of patients, the fall in serum bilirubin was more than $50 \%$ of initial value. 
Table 4 Different modes of management

\begin{tabular}{|c|c|c|c|c|c|c|c|c|c|c|}
\hline \multirow{2}{*}{ Management } & \multirow[b]{2}{*}{$\mathrm{N}$} & \multicolumn{4}{|c|}{ Benign etiology } & \multicolumn{5}{|c|}{ Malignant etiology } \\
\hline & & CDL & CDC & CBD stricture & MZ SYN & CAGB & CAPN & Periampullary CA & Chol CA & $\mathrm{HCC}$ \\
\hline PTBD & 17 & 0 & 0 & 0 & 0 & 14 & 0 & 2 & 0 & 1 \\
\hline ERCP and stent & 4 & 0 & 0 & 2 & 0 & 0 & 0 & 0 & 2 & 0 \\
\hline Cholecystostomy & 1 & 0 & 0 & 0 & 0 & 1 & 0 & 0 & 0 & 0 \\
\hline CBD exploration & 20 & 18 & 0 & 0 & 2 & 0 & 0 & 0 & 0 & 0 \\
\hline Choledochal cyst excision & 1 & 0 & 1 & 0 & 0 & 0 & 0 & 0 & 0 & 0 \\
\hline Whipple's procedure & 5 & 0 & 0 & 0 & 0 & 0 & 1 & 2 & 2 & 0 \\
\hline Bypass (CD) & 1 & 1 & 0 & 0 & 0 & 0 & 0 & 0 & 0 & 0 \\
\hline Hepaticojejunostomy & 1 & 0 & 0 & 0 & 0 & 0 & 0 & 0 & 1 & 0 \\
\hline Total & 50 & 19 & 1 & 2 & 2 & 15 & 1 & 4 & 5 & 1 \\
\hline
\end{tabular}

Abbreviations: CD, choledochoduodenostomy; CAGB, carcinoma of gallbladder; CAPN, carcinoma of pancreas; CBD, common bile duct; CDC, choledochal cyst; CDL, choledocholithiasis; Chol CA, cholangio carcinoma; ERCP, endoscopic retrograde cholangiopancreatography; HJ, hepaticojejunostomy; HCC, hepatocellular carcinoma; MZ SYN, Mirizzi’s syndrome; PTBD, percutaneous transhepatic biliary drainage.

- SGOT: After PTBD in 35\% of patients, the decrease in SGOT was between 10 and $50 \%$. In $52 \%$ of patients, there was increase in SGOT. After CBD exploration in $45 \%$ of patients, the fall in SGOT level was between 10 and 50\%. In 35\% of patients, there was increase in SGOT.

Serum ALP showed a significant decrease after PTBD. In 88.23\% of patients, the fall in ALP was between 10 and $50 \%$. In $11.26 \%$ of patients, decrease in value more than $50 \%$ was shown. Following CBD exploration with T-tube drainage, $65 \%$ of patients showed fall in value between 10 and $50 \%$. In $50 \%$ of patients, the decrease in value was greater than $50 \%$.

- PT: In $76.47 \%$ of patients, the decrease in PT was between 10 and $50 \%$. In $5.8 \%$ of patients, the decrease in value was greater than $50 \%$ following PTBD. After CBD exploration with T-tube drainage in $25 \%$ of patients, there was increase in value after biliary decompression.

- Albumin: In $70.58 \%$ of patients, there was increase in albumin level between 10 and 50\%. In 5.8\% of patients, there was decrease in value after PTBD. After CBD exploration in $40 \%$ of patients, there was decrease in albumin level between 10 and $40 \%$ of patients. In $10 \%$ of patients, there was decrease in the serum albumin.

\section{Discussion}

This study results were in consensus with most studies where malignant causes were the common reason for surgical obstructive jaundice, except the study conducted by Huis et al where most (74\%) cases were due to benign causes ${ }^{13}$ (-Tables 5 and 6 ).
This study findings were similar to the study conducted by Sharma et al, whereas as per studies conducted by Siddique et al and Huis et al, choledocholithiasis is the common etiology.

CBD exploration with T-tube drainage has higher values of decrease in serum bilirubin, serum bilirubin (indirect), serum ALP, and albumin when compared with the initial values in relation to biliary decompression after PTBD.

\section{Conclusion}

Obstructive jaundice has different etiologic spectrum in both males and females. Benign causes are seen at comparatively younger age group as compared with malignant causes. Gallbladder carcinoma was the most common malignant etiology, whereas choledocholithiasis was the most common benign cause. Irrespective of etiology, common presentation is pain (94\%), followed by pruritus (40\%). Most patients with malignant etiology presented with palpable lump. PTBD was

Table 5 Comparison of types of cancer with this study

\begin{tabular}{|c|c|c|}
\hline Study & Malignant causes (\%) & Benign causes (\%) \\
\hline Siddique et al ${ }^{11}$ & 56.66 & 43.33 \\
\hline Moghimi et al ${ }^{12}$ & 60.15 & 39.85 \\
\hline Huis et $\mathrm{a}^{13}$ & 25.83 & 74.17 \\
\hline Cheema et al ${ }^{14}$ & 65 & 35 \\
\hline Huang et al ${ }^{10}$ & 57.6 & 42.4 \\
\hline This study & 52 & 48 \\
\hline
\end{tabular}

Table 6 Comparison of various studies done for etiologic spectrum of obstructive jaundice

\begin{tabular}{|c|c|c|c|c|c|}
\hline Study & CAPN (\%) & CAGB (\%) & Cholangio carcinoma (\%) & Periampullary carcinoma (\%) & Choledocholithiasis (\%) \\
\hline Siddique et al $^{11}$ & 30 & 13.33 & 11.66 & 1.66 & 35 \\
\hline Sharma et $\mathrm{al}^{15}$ & 26.6 & 28.7 & 10.8 & 9.8 & 12.4 \\
\hline Huis et al Croatia ${ }^{13}$ & 11.9 & 3.3 & 4.6 & 4.6 & 74.1 \\
\hline This study & 2 & 57.6 & 19.8 & 7.06 & 38 \\
\hline
\end{tabular}

Abbreviations: CAGB, carcinoma of gallbladder; CAPN, carcinoma of pancreas. 
the most common method of biliary decompression in malignant group. CBD exploration with T-tube drainage has higher values of decrease in serum bilirubin, serum bilirubin (indirect), serum ALP, and albumin.

\section{Note}

Recommendations: Obstructive jaundice is a clinical diagnosis that requires both clinical and diagnostic workup to elucidate the precise etiology-a multidisciplinary approach that requires the better outcome.

\section{Conflict of Interest}

None declared.

\section{References}

1 Abrendt SA, Pitt HA, Angelica MD, Fong Y, eds. The liver. In: Townsend CM, Beachamp RD, Evers BM, Mattox KL, eds. Sabiston Textbook of Surgery. The Biological Basis of Modern Surgical Practice. 19th ed. Philadelphia, PA: Saunders; 2004:1426

2 Roche SP, Kobos R. Jaundice in the adult patient. Am Fam Physician 2004;69(2):299-304

3 Parks RW, Johnston GW, Rowlands BJ. Surgical biliary bypass for benign and malignant extrahepatic biliary tract disease. $\mathrm{Br}$ J Surg 1997;84(4):488-492

4 Siddique K, Ali Q Mirza S, et al. Evaluation of the aetiological spectrum of obstructive jaundice. J Ayub Med Coll Abbottabad 2008;20(4):62-66
5 Barkun JS, Chaudhury P, Barkun AN. Approach to the Jaundiced Patient. ACS Surgery: Principles and Practice. 2006:5-20

6 Thapa BR, Walia A. Liver function tests and their interpretation. Indian J Pediatr 2007;74(7):663-671

7 Friedman SF, Martin P, Munoz JS. Laboratory evaluation of the patient with liver disease. In: Hepatology: A Textbook of Liver Disease. Philadelphia, PA: Saunders; 2003;1:661-709

8 Grattagliano I, Calamita G, Cocco T, Wang DQ, Portincasa P. Pathogenic role of oxidative and nitrosative stress in primary biliary cirrhosis. World J Gastroenterol 2014;20(19):5746-5759

9 Howard ER. Biliary atresia. In: Blumgart LH, Fong Y, eds. Surgery of Liver \& Biliary Tract. 3rd ed. London, UK: WB Saunders; 2000:853-877

10 Huang JQ, Bao XJ, Lu XH. [The common causes and differential diagnosis of malignant jaundice] [in Chinese] Zhonghua Nei Ke Za Zhi 1993;32(6):400-404

11 Siddique K, Ali Q, Mirza S, et al. Evaluation of the aetiological spectrum of obstructive jaundice. J Ayub Med Coll Abbottabad 2008;20(4):62-66

12 Moghimi M, Marashi SA, Salehian MT, Sheikhvatan M. Obstructive jaundice in Iran: factors affecting early outcome. Hepatobiliary Pancreat Dis Int 2008;7(5):515-519

13 Huis M, Stulhofer M, Szerda F, Vukić T, Bubnjar J. [Obstruction icterus-our experience] [in Croatian] Acta Med Croatica 2006;60(1):71-76

14 Cheema KM, Ahmad F, Gondal SH. Evaluation of etiological incidence and diagnostic modalities in obstructive jaundice. Pak Postgrad Med J 2001;12:160-164

15 Sharma MP, Ahuja V. Aetiological spectrum of obstructive jaundice and diagnostic ability of ultrasonography: a clinician's perspective. Trop Gastroenterol 1999;20(4):167-169 